OPEN ACCESS

Edited and reviewed by: Lidia Santarpia

University of Naples Federico II, Italy

*Correspondence: Yuekang Zhang

2012zykyx@sina.cn

tORCID:

Hui Tang

orcid.org/0000-0002-1979-4715

Specialty section:

This article was submitted to

Clinical Nutrition

a section of the journal

Frontiers in Nutrition

Received: 18 October 2020

Accepted: 29 October 2020

Published: 23 November 2020

Citation:

Tang $H$, Cao $Y$, Yang $X$ and Zhang $Y$ (2020) Corrigendum: Egg Consumption and Stroke Risk: A

Systematic Review and

Dose-Response Meta-Analysis of

Prospective Studies.

Front. Nutr. 7:618715

doi: 10.3389/fnut.2020.618715

\section{Corrigendum: Egg Consumption and Stroke Risk: A Systematic Review and Dose-Response Meta-Analysis of Prospective Studies}

\author{
Hui Tang ${ }^{1,2+}$, Yi Cao ${ }^{1}$, Xiang Yang ${ }^{1}$ and Yuekang Zhang ${ }^{1 *}$ \\ ${ }^{1}$ Department of Neurosurgery, West China Hospital, Sichuan University, Chengdu, China, ${ }^{2}$ Department of Neurosurgery, \\ Nanchong Central Hospital, The Second Clinical Medical College, North Sichuan Medical College, Nanchong, China
}

Keywords: egg consumption, stroke risk, systematic review, meta-analysis, dose-response

\section{A Corrigendum on}

Egg Consumption and Stroke Risk: A Systematic Review and Dose-Response Meta-Analysis of Prospective Studies

by Tang, H., Cao, Y., Yang, X., and Zhang, Y. (2020). Front. Nutr. 7:153. doi:10.3389/fnut.2020.00153

In the original article, there was a mislabeled Figure 3 as published. The thirteenth and fourteenth labels in the leftmost column of Figure 3 should have read "Qin et al., 2018 Hemorrhagic stroke" and "Qin et al., 2018 Ischemic stroke". The corrected Figure 3 appears below.

The authors apologize for this error and state that this does not change the scientific conclusions of the article in any way. The original article has been updated.

Copyright $\odot 2020$ Tang, Cao, Yang and Zhang. This is an open-access article distributed under the terms of the Creative Commons Attribution License (CC BY). The use, distribution or reproduction in other forums is permitted, provided the original author(s) and the copyright owner(s) are credited and that the original publication in this journal is cited, in accordance with accepted academic practice. No use, distribution or reproduction is permitted which does not comply with these terms. 


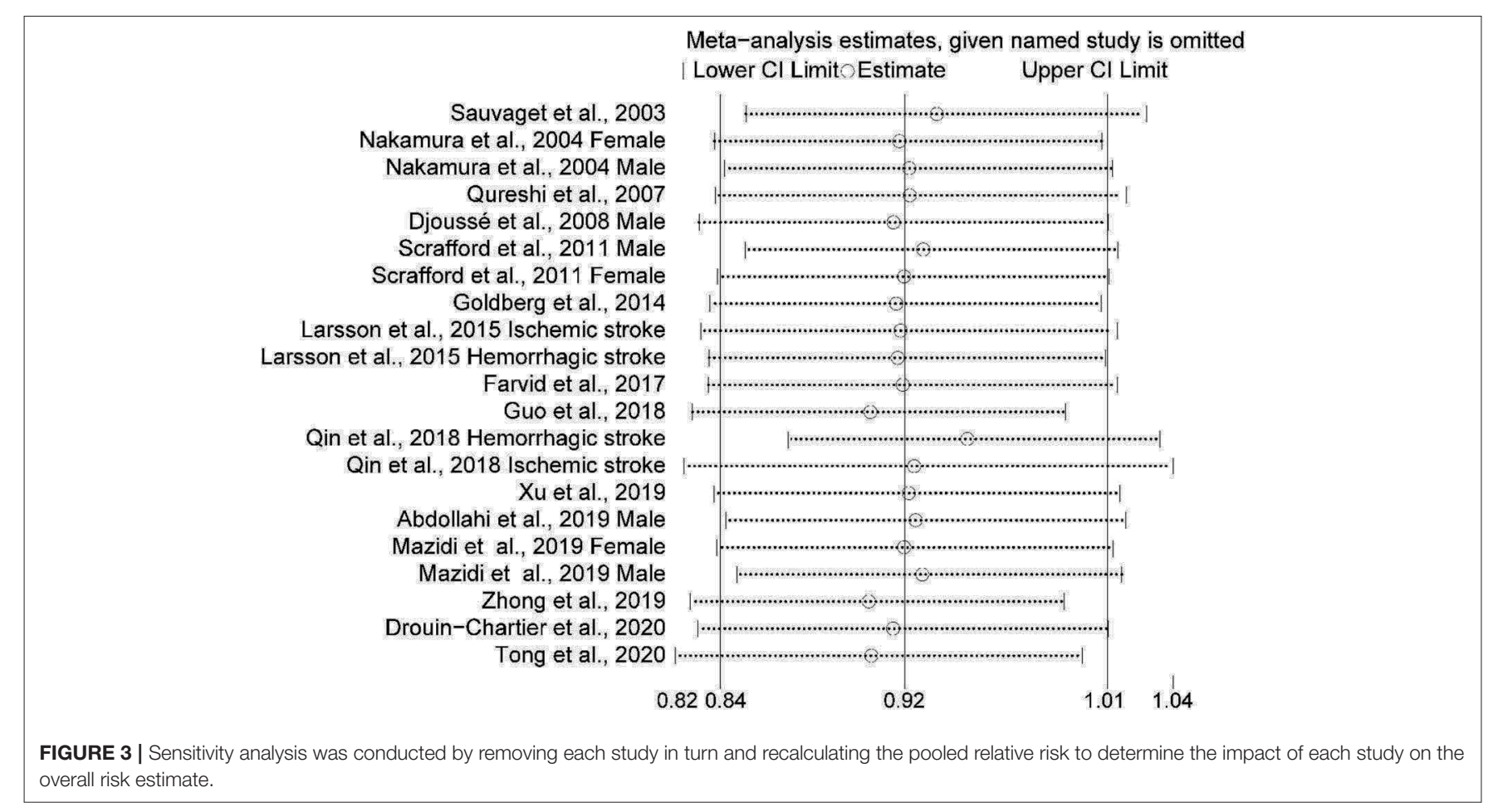

